\title{
Sensory-specific satiety for a food is unaffected by the ad libitum intake of other foods during a meal. Is SSS subject to dishabituation?
}

Citation for published version (APA):

Meillon, S., Thomas, A., Havermans, R., Penicaud, L., \& Brondel, L. (2013). Sensory-specific satiety for a food is unaffected by the ad libitum intake of other foods during a meal. Is SSS subject to dishabituation? Appetite, 63, 112-118. https://doi.org/10.1016/j.appet.2012.12.004

Document status and date:

Published: 01/01/2013

DOI:

10.1016/j.appet.2012.12.004

Document Version:

Publisher's PDF, also known as Version of record

Document license:

Taverne

Please check the document version of this publication:

- A submitted manuscript is the version of the article upon submission and before peer-review. There can be important differences between the submitted version and the official published version of record.

People interested in the research are advised to contact the author for the final version of the publication, or visit the DOI to the publisher's website.

- The final author version and the galley proof are versions of the publication after peer review.

- The final published version features the final layout of the paper including the volume, issue and page numbers.

Link to publication

\footnotetext{
General rights rights.

- You may freely distribute the URL identifying the publication in the public portal. please follow below link for the End User Agreement:

www.umlib.nl/taverne-license

Take down policy

If you believe that this document breaches copyright please contact us at:

repository@maastrichtuniversity.nl

providing details and we will investigate your claim.
}

Copyright and moral rights for the publications made accessible in the public portal are retained by the authors and/or other copyright owners and it is a condition of accessing publications that users recognise and abide by the legal requirements associated with these

- Users may download and print one copy of any publication from the public portal for the purpose of private study or research.

- You may not further distribute the material or use it for any profit-making activity or commercial gain

If the publication is distributed under the terms of Article $25 \mathrm{fa}$ of the Dutch Copyright Act, indicated by the "Taverne" license above, 
Research report

\title{
Sensory-specific satiety for a food is unaffected by the ad libitum intake of other foods during a meal. Is SSS subject to dishabituation? ${ }^{\text {is }}$
}

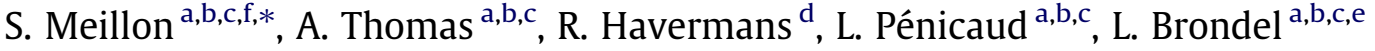 \\ ${ }^{a}$ CNRS, UMR 6265, Centre des Sciences du Goût et de l'Alimentation, F-21000 Dijon, France \\ ${ }^{\mathrm{b}}$ INRA, UMR 1324, Centre des Sciences du Goût et de l'Alimentation, F-21000 Dijon, France \\ ${ }^{\mathrm{c}}$ Université de Bourgogne, UMR, Centre des Sciences du Goût et de l'Alimentation, F-21000 Dijon, France \\ ${ }^{\mathrm{d}}$ Department of Clinical Psychological Science, Faculty of Psychology E Neuroscience, Maastricht University, P.0. Box 616, 6200 MD Maastricht, The Netherlands \\ 'Service d'Hépato-Gastroentérologie, CHU Dijon, Dijon, France \\ ${ }^{\mathrm{f}}$ CSGA, 9 E bd Jeanne d'Arc, 21000 Dijon, France
}

\section{A R T I C L E I N F O}

\section{Article history:}

Received 27 September 2012

Received in revised form 3 December 2012

Accepted 5 December 2012

Available online 21 December 2012

\section{Keywords:}

Sensory-specific satiety

Dishabituation

Pleasantness

Food intake

Meal

\begin{abstract}
A B S T R A C T
Sensory-specific satiety (SSS) is defined as a decrease in the pleasantness of a specific food that has just been eaten to satiation, while other non-eaten foods remain pleasant. The objectives of this study were the following: (1) to investigate whether SSS for a food is affected by the ad libitum intake of other foods presented sequentially during a meal, (2) to compare the development of SSS when foods are presented simultaneously or sequentially during a meal, and (3) to examine whether SSS is modified when foods are presented in an unusual order within a meal. Twelve participants participated in three tasting sessions. In session A, SSS for protein-, fat- and carbohydrate-rich sandwiches was measured after the ad libitum consumption of single type of each of these foods. In session B, SSS was measured for the same three foods consumed ad libitum but presented simultaneously. Session C was identical to session A, except that the presentation order of the three foods was reversed. The results indicate that once SSS for a given food is reached, the ad libitum consumption of other foods with different sensory characteristics does not decrease SSS, regardless of the order in which the foods are presented. Once reached, SSS is thus not subject to dishabituation during a meal.
\end{abstract}

(c) 2012 Elsevier Ltd. All rights reserved.

\section{Introduction}

Sensory-specific satiety (SSS) is defined as a decrease in the pleasantness of a specific food that has just been eaten to satiation, while other non-eaten foods with different sensory characteristics remain pleasant. SSS is a form of negative alliesthesia (the affective part of a sensation) in which the pleasure induced by a stimulus decreases until that stimulus becomes neutral or even unpleasant (Cabanac, 1971). SSS plays an important role in food intake and food choice by promoting the end of an eating bout and the search for food variety (Hetherington \& Rolls, 1996).

The mechanisms involved in the development of SSS are not completely understood. SSS is assumed to be a primarily sensory-based phenomenon because it is not related to post-ingestive and post-absorptive effects of food ingestion. Indeed, SSS is

\footnotetext{
Acknowledgements: We gratefully acknowledge Philip Bastable of the "Research Pole" of Dijon University Hospital for revising the English. We also gratefully acknowledge Michael A. Romer for reviewing the manuscript and for his useful advice.

* Corresponding author.

E-mail address: sophie.meillon@dijon.inra.fr (S. Meillon).
}

reached quickly after food ingestion (Rolls, Rolls, Rowe, \& Sweeney, 1981), and sensory stimulation without ingestion (sham feeding) leads to partial SSS (Rolls \& Rolls, 1997; Smeets \& WesterterpPlantenga, 2006). The sensory properties of a food that contribute to the development of SSS include its smell (Rolls \& Rolls, 1997), taste (Brondel, Lauraine, Van Wymelbeke, Romer, \& Schaal, 2009; Rolls \& Rolls, 1997), texture (Guinard \& Brun, 1998), and visual appearance (colour and shape) (Rolls, Rowe, \& Rolls, 1982). SSS is not the result of a decrease in taste sensitivity because the decrease in the pleasantness of a food eaten ad libitum is not related to one's capacity to detect a decrease in taste intensity (Rolls, Rolls, \& Rowe, 1983). A study conducted in nonhuman primates confirmed that the responsiveness of gustatory neurons in the nucleus tractus solitarius (NTS) is not decreased after repeated presentations of sweet foods (Yaxley, Rolls, Sienkiewicz, \& Scott, 1985).

SSS is thought to result from a habituation mechanism (Epstein, Temple, Roemmich, \& Bouton, 2009). Habituation is defined as a decrease in responsiveness to a stimulus when that stimulus is presented repeatedly or for a prolonged time (Groves \& Thompson, 1970). This decrease appears to be a central neural process because it is specific to one stimulus; the responses to other stimuli recover (Thompson \& Spencer, 1966). Habituation is considered to be a 
form of learning that allows "animals/humans to filter out irrelevant stimuli and focus selectively on important stimuli" (Rankin et al., 2009). In the case of SSS, habituation induces reductions in both physiological and behavioural responses to eating, i.e., foodspecific decreases in salivation (Epstein, Rodefer, Wisniewski, \& Caggiula, 1992), pleasure (Rolls et al., 1983) or wanting for the food (Havermans, Janssen, Giesen, Roefs, \& Jansen, 2009). Neurobiological studies in nonhuman primates (Rolls, Critchley, Browning, Hernadi, \& Lenard, 1999; Rolls, Sienkiewicz, \& Yaxley, 1989) and humans (O'Doherty et al., 2000) have confirmed the existence of a food-specific habituation mechanism by demonstrating both a decrease in the response of neurons in the orbitofrontal cortex to a food eaten to satiety and a recovery in the response to other foods not eaten to satiety.

In a review, Thompson and Spencer (1966) showed that there are nine general characteristics of the habituation response. The description of one of these characteristics was revised and refined by Rankin et al. (2009), who determined that when habituation occurs, the "presentation of a different stimulus results in an increase in the decremented response to the original stimulus. This phenomenon is termed "dishabituation". Is this characteristic applicable to the SSS response, and is SSS subject to dishabituation?

In other words, if SSS is a habituation mechanism, the pleasantness of a food eaten ad libitum should be restored, at least in part, when a new food is introduced (dishabituation). In accordance with this hypothesis, several studies have shown that the presence of dishabituating stimuli, such as food variety or a distraction (e.g., $\mathrm{TV}$, music or video games), during ingestion promotes food intake and delays the development of SSS (Brondel, Romer, Van Wymelbeke, Pineau, Jiang, et al., 2009; Epstein et al., 1992; Hetherington, Foster, Newman, Anderson, \& Norton, 2006). However, to our knowledge, only one study has examined whether the introduction of a new food can restore the pleasantness of a food that was recently eaten ad libitum. Indeed, Havermans (Havermans, 2012) observed that once SSS for a test food was established, neither the consumption of a new food nor distraction by a computer game dishabituated the SSS for the test food. Therefore, these findings suggested that SSS is not subject to dishabituation.

To our knowledge and in agreement with the findings of Havermans (Havermans, 2012), the process of SSS for foods eaten during a multicourse meal has never been studied. In Western countries, meals generally consist of three consecutive courses. One might wonder how SSS for a course eaten ad libitum might evolve after other courses had been eaten ad libitum. Is SSS for a course subject to dishabituation when other courses are eaten ad libitum afterwards?

The main objective of our study was to investigate whether SSS for a food is affected by the ad libitum intake of other foods presented sequentially during a meal. The secondary objectives of our study were to compare the development of SSS during a meal in which foods are presented sequentially with that during a meal in which foods are presented simultaneously and to examine whether SSS is affected when foods are presented in an unusual order during a meal.

\section{Methods}

\section{Participants}

Twelve participants (six men and six women) were recruited from the undergraduate student population of the University of Dijon, France. To be included, participants had to be between 20 and 35 year of age and in good health. The exclusion criteria were the following: pregnancy; pathologies such as diabetes, impaired renal function and acute and chronic infection; smoking (more than five cigarettes/day); aversion for any of the foods consumed during the study. All the participants provided written consent to participate in the experiment, which was approved by the Regional Ethics Committee of Burgundy (France).

\section{General procedure}

The participants participated in three 30-min sessions (A, B and $C)$ in the Centre for Taste and Feeding Behaviour in Dijon. Sessions A and B were separated by a 7-day interval, and the order of the sessions was randomised. Session $C$, which had not been planned prior to the commencement of the experiment, was conducted 3 weeks after the second session in order to complete the study. Each session began at 10 a.m. and occurred in isolated sensory booths that were maintained at a standardised temperature $\left(20 \pm 1^{\circ} \mathrm{C}\right)$. The participants were instructed to not eat, drink or smoke during the morning of a test and to fast between the test and the evening meal on the preceding night.

Before and after a snack (see below), the participants indicated their level of hunger using a $100-\mathrm{mm}$ visual analogue scale that was anchored at its ends by the statements "not at all hungry" $(0)$ and "very hungry" $(+100)$. The participants also indicated the intensity of their desire to eat at that moment using a $100-\mathrm{mm}$ visual analogue scale that was anchored by the statements "not at all" (0) and "very much" (+100).

\section{Food stimuli and snack intake}

In each session, a snack was offered. This snack consisted of six different types of open sandwich served on a plate. The choices comprised one slice of white sandwich bread (Harry's Moelleux, Barilla and Fratelli Corp., Parma, Italy; $17 \mathrm{~g}, 194.7 \mathrm{~kJ}$ ) with $15 \mathrm{~g}$ of either turkey ham, duck breast, cheese, butter, jam or honey and cut into nine equal, square pieces measuring $30 \mathrm{~mm} \times 30 \mathrm{~mm}$. Therefore, the sandwiches were rich in either protein, fat, or carbohydrate. The protein-rich sandwiches were the turkey ham (Blanc de Dinde, Carrefour, France; proteins: 91 p.100 w/w total nutrients) and duck breast sandwiches (Magret de canard du Sud-Ouest fume, Delpeyrat, France; proteins: 67 p. $100 \mathrm{w} / \mathrm{w}$ total nutrients). The butter (Beurre tendre, Elle \& Vire, France; lipids: 98 p.100 w/ $\mathrm{w}$ total nutrients) and cheese spread sandwiches (Fromage à la crème, Elle $\&$ Vire, France; lipids: 73 p.100 w/w total nutrients) were fat-rich. The carbohydrate-rich sandwiches were the strawberry jam (Confiture de fraises, Carrefour, France; carbohydrates: 99 p.100 w/w total nutrients) and honey (Miel Mille Fleurs, Lune de miel, France; carbohydrates: 99 p.100 w/w total nutrients) sandwiches. The energy contents of the turkey ham, duck breast, butter, cheese, jam and honey sandwiches were 36.8, 41.9, 83.7, 48.1, 49.8 and $51.1 \mathrm{~kJ}$, respectively.

The meal presented in this study was simplified for practical reasons, and sandwiches were chosen to standardise the volume of the foods ingested in each course. The sandwich ingredients were chosen because they strongly evoked the sensory properties (smell, taste, texture and appearance) associated with proteins, fats or sweets, rather than for their macronutrient content. Specifically, turkey ham and duck breast were associated with a strong "protein image", butter and fat cheese were associated with a strong "fat image", and honey and strawberry jam were associated with a strong "sweet image".

\section{Procedure for sessions $A, B$ and $C$}

During the first session, the participants tasted and rated their liking of the six different sandwiches. After this first rating, the experimenter selected the more highly rated of each type of sandwich (protein-, fat- and carbohydrate-rich) to serve as the snack. 
This selection was recorded and kept for the two following sessions.

\section{Snack during session A}

After rating their liking of the six different sandwiches, the participants were presented with a tray containing 24 sandwiches of the selected protein-rich variety. They were invited to eat as many sandwiches as they wanted (ad libitum intake). If the participants ate all the sandwiches on the tray, they were provided with another tray containing 24 sandwiches. Once the participants stopped eating, they were offered a plate with the six different sandwiches to reevaluate their liking of the sandwiches. Then, they were presented with a second tray containing 24 sandwiches of the selected fat-rich variety, which were eaten ad libitum. After this, the scores for the liking of the six different sandwiches were evaluated as before, and a third tray containing 24 sandwiches of the selected carbohydrate-rich variety was then presented for ad libitum consumption. The liking of the six different sandwiches was evaluated again.

\section{Snack during session $B$}

After rating their liking of the six types of sandwich, the participants were offered a tray containing 48 pieces of the three selected sandwiches (16 protein-, 16 fat- and 16 carbohydrate-rich pieces). The participants were instructed to eat as much as they wanted (ad libitum intake) of the sandwiches they liked. If they finished one type of sandwich, another complete tray was served, and so on. Once the participants stopped eating, their liking of the six different sandwiches was evaluated again.

\section{Snack during session $C$}

Session $C$ was exactly the same as session A, except that the sandwiches were presented in a different order: the participants first ate the carbohydrate-rich, then the fat-rich and finally the protein-rich sandwiches.

Figure 1 summarises the procedures for sessions A, B and C.

The presentation order of the sandwiches selected in session A (sandwiches with a strong "protein image", then those with a strong "fat image" and then those with a strong "sweet image") was intended to correspond to a typical French meal pattern, in which a main meat-centred dish is eaten, followed by cheese with bread and then a dessert. The influence of the presentation order of the sandwiches was evaluated in session $C$ (sandwiches with a strong "sweet image", then those with strong "fat image" and then those with a strong "protein image") because this ordering did not correspond to a typical Western meal. In session $\mathrm{B}$, the participants were free to choose the order in which they ate the sandwiches (which were served simultaneously) to compare the effects of free and forced choices.

After the snack, the number of each type of sandwich eaten was recorded without the knowledge of the participants. Liking of the six different sandwiches was evaluated again one hour after the end of the snack.

Sensory-specific satiety and postprandial changes in liking evaluations

Liking of each of the six different sandwiches was evaluated with the following question: "How much do you like the taste of this food now?" using a 100-mm visual analogue scale anchored at its ends by the statements "I do not like it at all" (0) and "I like it very much" $(+100)$.

The degree of SSS was measured as the difference between the final and initial liking ratings of the sandwich that was eaten. The postprandial change in liking was measured as the difference between the liking rating evaluated one hour after the snack and the final-liking rating.

\section{Statistical analysis}

The values are expressed as the means \pm SD. The statistical analyses were divided into two steps: the evolution of the different variables in session $A$ and a comparison of the different variables between session $B$ or $C$ and session $A$.

For session A, the evolution of liking ratings was analysed separately for each type of sandwich using a two-way repeated measures ANOVA with ingestion (eaten $v$ s. non-eaten sandwiches) and tasting bout (before snack intake, after protein intake, after fat intake, after carbohydrate intake or $1 \mathrm{~h}$ after carbohydrate intake) as factors. Two-way repeated measures ANOVAs with ingestion and type of sandwich (protein, fat or carbohydrate) as factors were also used to analyse the differences in the liking of the eaten and noneaten sandwiches between before and after the ingestion of each type of sandwich. Fisher's least-significant difference (LSD) post hoc test was performed when one factor was found to significantly isolate a group from the others. Hunger sensations and the desire to eat were compared before and after the snack using Student's paired $t$-test. The numbers of the different types of sandwiches eaten during the session were compared using a one-way repeated measures ANOVA.

Regarding the comparison of session $B$ or $C$ with session $A$, three-way repeated measures ANOVAs with session, type of
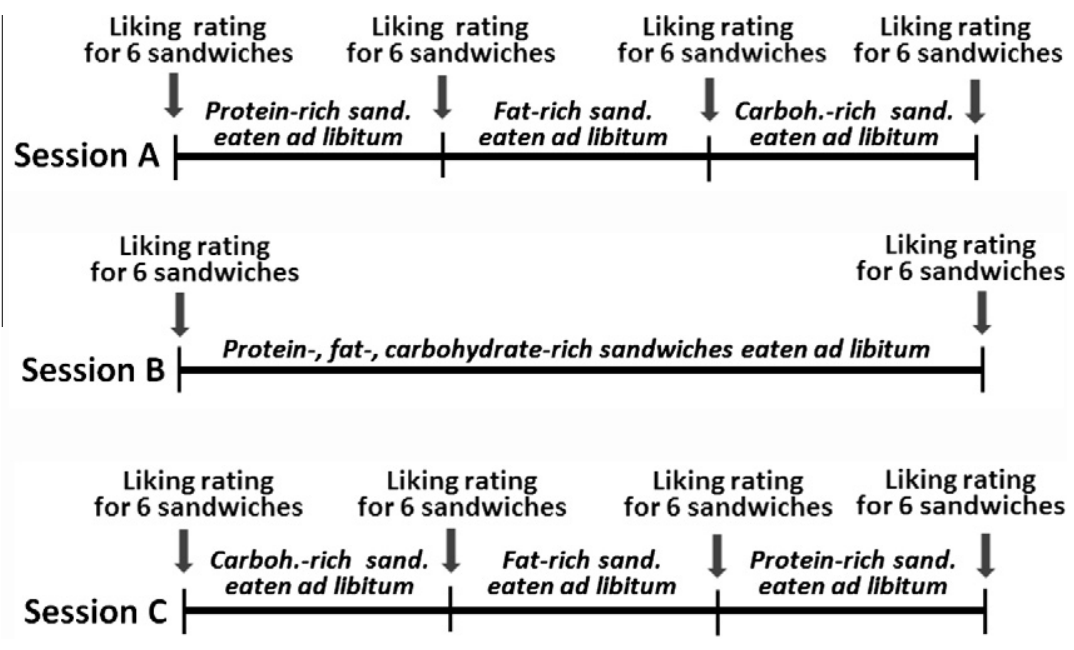

Fig. 1. Procedures for sessions A, B and C. 
sandwich and ingestion as factors were used to analyse the changes in liking ratings from before to after the consumption of the snack. Fisher's least-significant difference (LSD) post hoc test was performed when a factor was found to significantly isolate a group from the others. Student's paired t-tests were also performed to compare the hunger sensations and the desire to eat in session B or C with those in session A. A one-way repeated measures ANOVA with session as factor was performed on the number of sandwiches eaten.

The analyses were conducted using R software (version 2.14.0, R Development Core Team, Vienna, Austria), and the level of statistical significance was set at $\alpha=0.05$.

\section{Results}

Upon inclusion, the age (mean \pm SD) of the participants was $25 \pm 4$ year, and their body mass index was $22 \pm 4 \mathrm{~kg} \mathrm{~m}^{-2}$.

\section{Evolution of food liking and intake in session $A$}

The reported hunger sensations and desire to eat decreased from before to after the snack $(-61 \pm 16$ and $-45 \pm 12$, respectively; $p<0.001$ for both). Overall, the participants consumed $41 \pm 26$ sandwiches (i.e., $1126 \pm 717 \mathrm{~kJ}$ ) and ate more protein-rich sandwiches $(23 \pm 23)$ than fat- or carbohydrate-rich sandwiches ( $9 \pm 9$ and $9 \pm 7$, respectively; $p=0.05$ for both).

Figure 2 shows the evolution of the liking ratings for the six sandwiches. The two-way repeated measures ANOVA revealed significant effects of ingestion (protein: $F=6.27, p<0.05$; fat: $F=18.65, p<0.0001$; carbohydrate: $F=30.11, p<0.0001)$ and tasting bout (protein: $F=8.80, p<0.0001$; fat: $F=6.36, p<0.001$; carbohydrate: $F=7.78, p<0.0001$ ) and no significant interaction between the two factors. Fisher's LSD post hoc tests indicated the following: (i) the eaten sandwiches had higher liking ratings than the non-eaten ones $(p<0.05)$, (ii) the liking ratings decreased after the ingestion of the eaten sandwiches $(p<0.05)$ and remained low and stable thereafter (although another type of sandwich was eaten), and (iii) the liking ratings for the non-eaten protein- and carbohydrate-rich sandwiches decreased during the ingestion of the eaten protein- and carbohydrate-rich sandwiches $(p<0.05)$.

The two-way repeated measures ANOVA with ingestion and type of sandwich as factors revealed a significant effect of ingestion $(F=5.88 ; p<0.05)$ but no significant effect of the type of sandwich eaten. Fisher's LSD post hoc test indicated that the eaten sandwiches induced a significantly greater reduction in liking compared to the non-eaten ones $(-21 \pm 3 v s .-10 \pm 3, p<0.05)$.

Therefore, these results show that once SSS is established for a given food, it is not decreased by the subsequent ad libitum consumption of other foods with different sensory characteristics. Furthermore, SSS remains active for at least one hour after the end of the food intake.

Liking and intake after the sequential or simultaneous presentation of the sandwiches (session A vs. session B)

The pre- and postprandial hunger sensations and the desire to eat did not differ between sessions $A$ and $B$. The total number of sandwiches eaten was also similar between these sessions ( $41 \pm 26$ and $35 \pm 18$, respectively), with no difference between the numbers of protein-, fat- and carbohydrate-rich sandwiches eaten (Fig. 3).

Figure 4 shows the changes in liking of the sandwiches eaten from before to after the snack and during the postprandial period. The results of the three-way repeated measures ANOVA (session $\times$ type of sandwich $\times$ ingestion) performed on the decrease
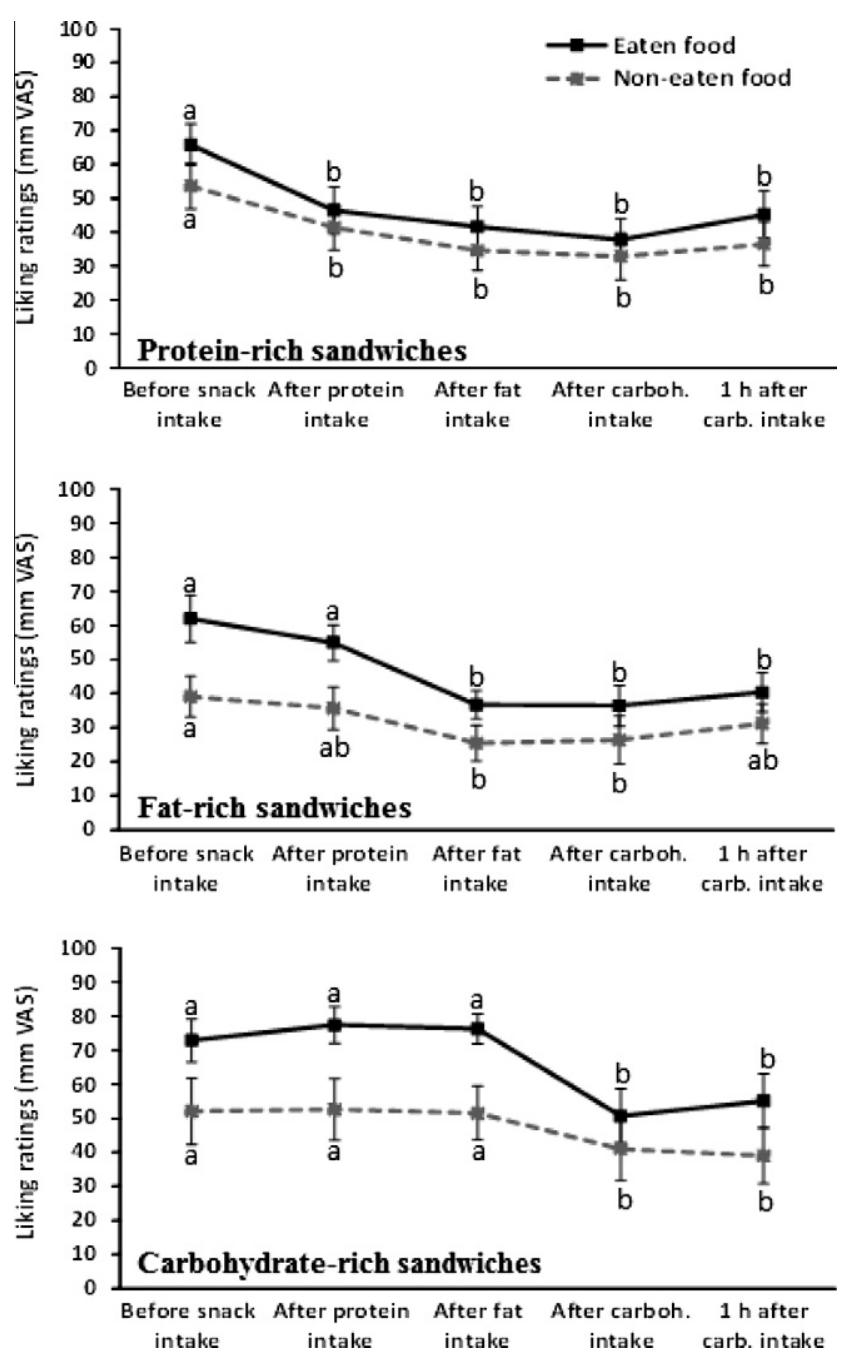

Fig. 2. Evolution of the liking ratings (means \pm SEM) for the eaten and non-eaten protein-, fat- and carbohydrate-rich sandwiches over time in session A, evaluated with $100-\mathrm{mm}$ visual analogue scales (VAS). ${ }^{\mathrm{a}}$ Means with the same letter within a curve are not significantly different (LSD test, $\alpha=0.05$ ).

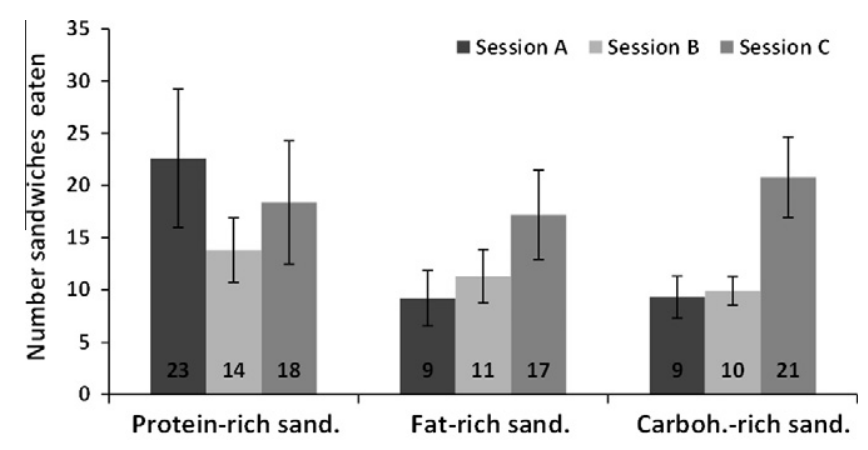

Fig. 3. Total number of protein-, fat- and carbohydrate-rich sandwiches eaten in sessions $\mathrm{A}, \mathrm{B}$ and $\mathrm{C}$.

in liking from before to after the snack indicated a significant effect of ingestion $(F=3.88 ; p=0.050)$, but no effect of session or type of sandwich. Neither the second- nor the third-order interactions were significant. Fisher's LSD post hoc test indicated only that the eaten sandwiches produced greater liking ratings than the non-eaten ones $(p<0.05)$.

Together, these results indicate that SSS developed in the same way, regardless of whether the three types of sandwiches were 


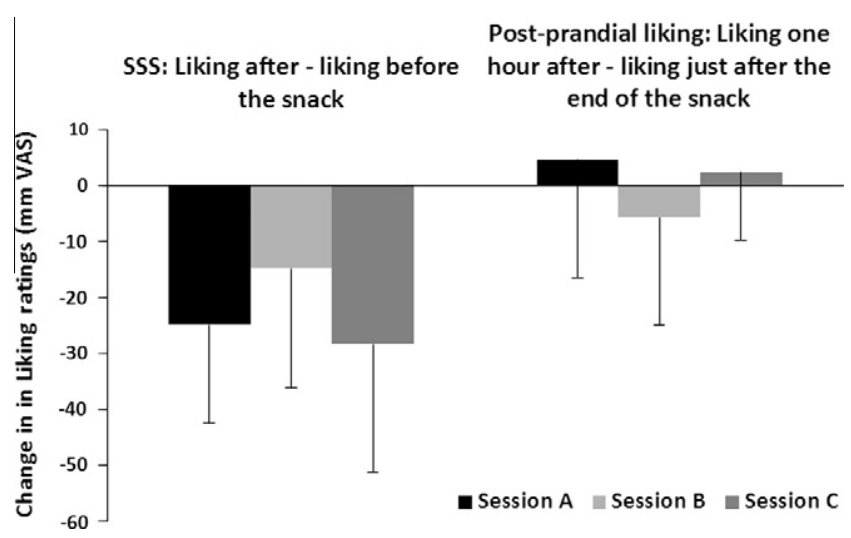

Fig. 4. Changes in the liking ratings (means \pm SEM) for the eaten protein-, fat- and carbohydrate-rich sandwiches in sessions A, B and C, evaluated with 100-mm visual analogue scales (VAS)

presented sequentially or simultaneously. Our results also indicate similar ingestion of the sandwiches (type and amount) regardless of the order of sandwich presentation.

Liking and intake after the usual or unusual presentation order of the sandwiches (session A vs. session C)

The pre- and postprandial hunger sensations and the desire to eat did not differ between sessions $A$ and $C$. The participants consumed more sandwiches during session $C$ than during session $A$ ( $56 \pm 40 v s .41 \pm 26, p<0.05$ ). There were no significant differences in the numbers of protein-, fat- and carbohydrate-rich sandwiches eaten between the two sessions. However, a smaller proportion of the protein-rich sandwiches $(p<0.01)$ and a larger proportion of the carbohydrate-rich sandwiches $(p<0.05)$ were eaten during session C compared to session A (Fig. 3 ).

The results of the three-way repeated measures ANOVA (session $\times$ type of sandwich $\times$ ingestion) performed on the decrease in liking from before to after the snack indicated a significant effect of ingestion $(F=8.3 ; p<0.01)$, but no effect of session or type of sandwich. Neither the second- nor the third-order interactions were significant. Fisher's LSD post hoc test indicated that the eaten sandwiches induced a greater decrease in liking than the non-eaten ones $(p<0.05)$.

Figure 5 shows the evolution of the liking ratings for the six sandwiches in session C. The two-way repeated measures ANOVA with ingestion and tasting bout as factors revealed significant effects of ingestion (protein: $F=23.24, p<0.001$; fat: $F=10.20$, $p<0.01$; carbohydrate: $F=13.27, p<0.001$ ) and tasting bout (protein: $F=9.42, p<0.001$; fat: $F=12.81, p<0.001$; carbohydrate: $F=12.24, p<0.001)$ and no significant interaction between the two factors. Fisher's LSD post hoc tests indicated the following: (i) the eaten sandwiches received higher liking ratings than the non-eaten ones $(p<0.5)$, (ii) the liking ratings decreased after the ingestion of the eaten sandwiches $(p<0.05)$ and remained low and stable thereafter, and (iii) the liking ratings for the non-eaten protein- and carbohydrate-rich sandwiches decreased during the ingestion of the eaten protein- and fat-rich sandwiches $(p<0.05$ for both).

These results indicate that the unusual order of consumption (the protein-, then the fat- and then the carbohydrate-rich sandwiches) had no significant impacts on SSS or the evolution of the liking ratings; however, it significantly increased the total number of sandwiches eaten and the proportion of the type of sandwich eaten first.
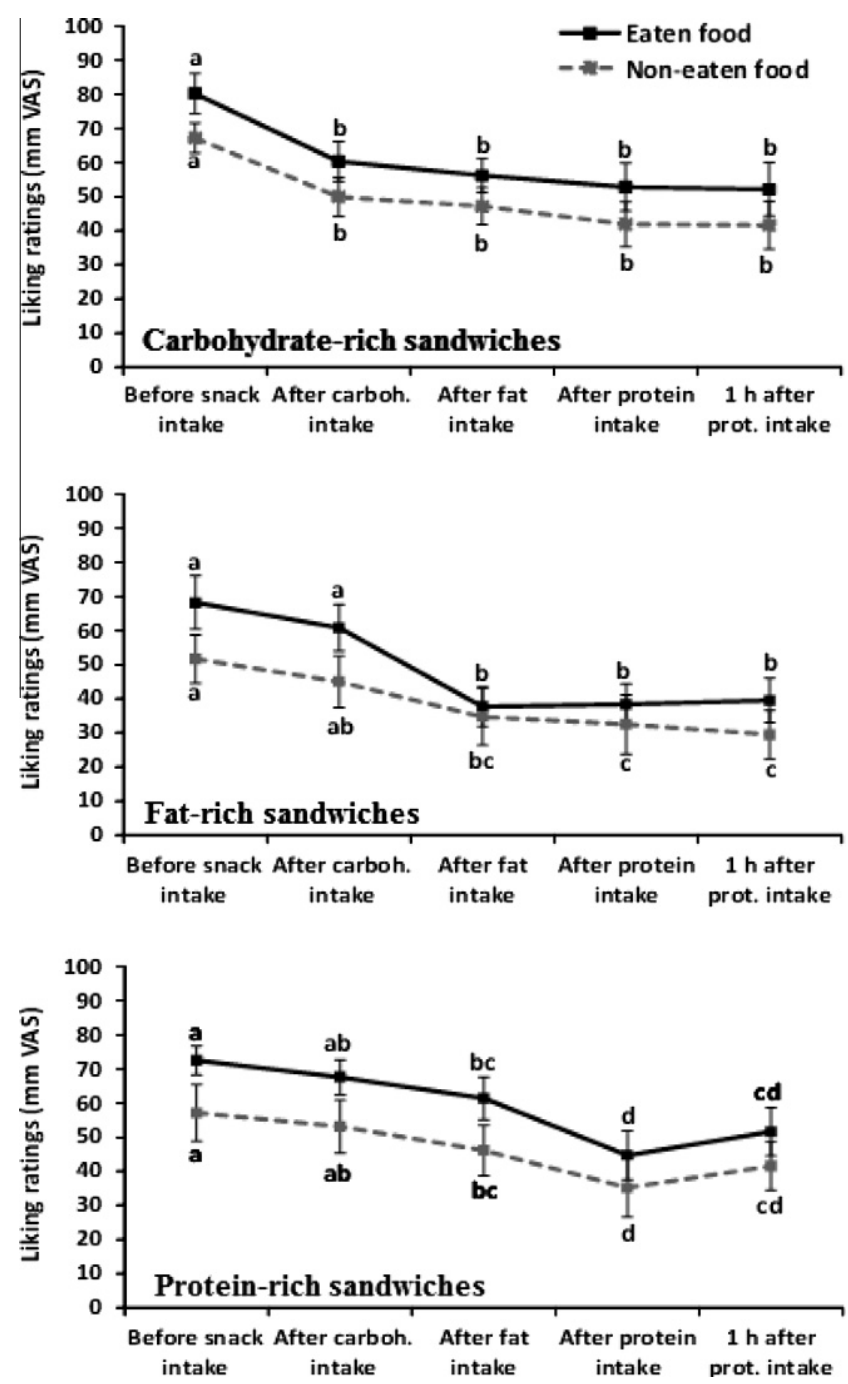

Fig. 5. Evolution of the liking ratings (means \pm SEM) for the eaten and non-eaten carbohydrate-, fat- and protein-rich sandwiches over time in session $\mathrm{C}$, evaluated with $100-\mathrm{mm}$ visual analogue scales (VAS). ${ }^{\text {a }}$ Means with the same letter within a curve are not significantly different (LSD test, $\alpha=0.05$ ).

\section{Discussion}

To our knowledge, this is the first study to assess the evolution of SSS during a simplified meal with the successive consumption of protein-, fat- and carbohydrate-rich foods eaten ad libitum. The results indicate that once SSS is established for a given food, the ad libitum consumption of other foods with different sensory characteristics does not reverse the SSS, even when the foods are presented in an unusual order. The results also show that SSS develops similarly whether different ad libitum courses are presented sequentially or simultaneously during a meal.

SSS is thought to be the result of a habituation process. According to the description of habituation characteristics by Rankin et al. (2009), we would expect that experiencing a new food with different sensory characteristics during a meal would induce a decrease in SSS for the food/course previously eaten ad libitum. However, under the experimental conditions of the present study, such a modulation of SSS did not occur after the ad libitum intake of a new food; once established, SSS remained stable for one hour. This observation is in accordance with the findings of Havermans, who concluded that "SSS is insensitive to dishabituation" (Havermans, 2012). That author observed that when SSS was established for a 
given food, the (twice) repeated consumption of another food (two bite-size portions eaten carefully over $10 \mathrm{~min}$ ) did not dishabituate SSS. In contrast, these results differ from those of Romer et al. (2006), who reported a decrease in the olfactory pleasure derived from foods eaten ad libitum (i.e., SSS), which was partially reversible after the ingestion of a new food. However, the recovery observed in this study was weaker (approximately +0.5 points) than the three-point decrease in pleasantness (SSS). In addition, we cannot exclude the possibility that the recovery observed was due not to the second food eaten but to a spontaneous recovery because the increase in olfactory pleasure began shortly before the intake of the second food. In contrast, several studies have shown that food variety enhances food intake and delays the development of SSS, suggesting that SSS may be sensitive to dishabituation (Brondel, Lauraine, et al., 2009; Brondel, Romer, et al., 2009; Hetherington et al., 2006; Nolan \& Hetherington, 2009). These studies do not contradict our results because their presentation of the varied foods occurred before satiation (i.e., before the ad libitum intake and before the complete instauration of SSS). Taken together, these results suggest that, once established, SSS is no longer subject to dishabituation; however, the initial development of SSS is subject to dishabituation.

Therefore, we propose the following hypotheses: (i) SSS is the result of a habituation process, as suggested by numerous authors (Epstein et al., 2009; Hetherington \& Rolls, 1996); (ii) once established, i.e., after ad libitum intake, SSS is not sensitive to dishabituation for one hour, and the introduction of dishabituators such as new foods or watching TV does not restore the pleasantness of the food just eaten ad libitum (Havermans, 2012); and (iii) before SSS is completely established, dishabituators can delay and disrupt the development of SSS (Brondel, Lauraine, et al., 2009; Hetherington et al., 2006). The idea that SSS involves sensory stimulation, as do other habituation processes, but also involves the physical input of the stimulus into the body (ingestion) argues in favour of this hypothesis. Therefore, the process of SSS may occur in two phases: first, the repetition of the sensory signals leads to habituation and a decrease in the pleasantness of the food eaten, which can be dishabituated with a new food; next, the ad libitum ingestion reinforces the decrease in pleasantness with a sensation of fullness/satiation that can no longer be dishabituated by a new food. This hypothesis may also explain the lower decrease in SSS observed after experimental sham-feeding compared to after normal ingestion (Rolls \& Rolls, 1997; Smeets \& Westerterp-Plantenga, 2006).

The present results also indicate that SSS developed similarly whether the different types of sandwich were presented sequentially (sessions A and C) or simultaneously (session B). In contrast, the consumption of the sandwiches was affected by the presentation order of the foods; i.e., when the foods were presented in an unusual order (sandwiches with a strong "sweet image", then those with a strong "fat image" and then those with a strong "protein image") that is not typical for a Western meal, the total intake was higher that when the foods were presented in the usual order (sandwiches with a strong "protein image", then those with a strong "fat image" and then those with a strong "sweet image", as in a typical French meal). In contrast, the intakes were similar when the sandwiches were presented in the usual order and in a simultaneous session in which the participants chose the composition of their meal (unfortunately, the order of consumption was not recorded). As reviewed by Higgs (2008), cognitive factors influence food intake because anticipated and remembered pleasure are essential components of the decision to eat. Therefore, we hypothesise that the unusual presentation order of the sandwiches may have affected cognitive factors and increased the subsequent intake, although we have not identified these factors (a disruption in the memory encoding of the previous ingestion? a perturbation of the participants' references?). To investigate the effects of food presentation order on intake, further studies should be conducted to evaluate the influences of these cognitive factors.

A transfer effect was observed in this study: during sessions A and $C$, when the participants ate the protein- and carbohydraterich sandwiches, their liking ratings for the non-eaten proteinand carbohydrate-rich sandwiches also decreased. These decreases in the liking ratings for the non-eaten sandwiches were significantly smaller than those for the eaten sandwiches. These decreases were also specific because the liking ratings for the other types of sandwiches did not change. A transfer effect has previously been reported for foods with different flavours that share the same general sensory characteristics, such as sweet or savoury/salty (Griffioen-Roose, Finlayson, Mars, Blundell, \& de Graaf, 2010; Guinard \& Brun, 1998; Olsen, Ritz, Hartvig, \& Møller, 2011; Rolls, Van Duijvenvoorde, \& Rolls, 1984). In the present study, the transfer effect most likely affected the global sensory properties of the sandwiches (i.e., both protein-rich sandwiches were salty, meaty and had a fibrous texture; both fat-rich sandwiches were creamy, slightly salty and contained few aromatics; and both carbohydrate-rich sandwiches were sweet, contained high concentrations of fruit/flower aromatics and had a soft/melting texture) and the sensory "image" of the foods (i.e., the specific attributes of the macronutrient content).

In conclusion, once SSS is established for a given food, the consumption of other foods with different sensory characteristics does not decrease SSS during a simplified three-course meal. Although this result suggests that SSS is not subject to dishabituation after ad libitum intake, it does not exclude the possibility that SSS is induced by a habituation process. From a methodological point of view, our findings indicate that it is not necessary to assess the liking of foods after each new food is introduced during a meal and that only two ratings (before and after the ingestion of all the foods) are sufficient for evaluating SSS. From a practical point of view, this study suggests the necessity of avoiding complete SSS when trying to increase the intake levels of malnourished patients. Instead, the numbers of small portions of different foods with different sensory attributes (variety) should be increased.

\section{References}

Brondel, L., Lauraine, G., Van Wymelbeke, V., Romer, M., \& Schaal, B. (2009). Alternation between foods within a meal. Influence on satiation and consumption in humans. Appetite, 53(2), 203-209.

Brondel, L., Romer, M., Van Wymelbeke, V., Pineau, N., Jiang, T., Hanus, C., et al. (2009). Variety enhances food intake in humans. Role of sensory-specific satiety. Physiology and Behavior, 97(1), 44-51.

Cabanac, M. (1971). Physiological role of pleasure. Science (New York, N.Y.), 173(4002), 1103-1107.

Epstein, L. H., Rodefer, J. S., Wisniewski, L., \& Caggiula, A. R. (1992). Habituation and dishabituation of human salivary response. Physiology and Behavior, 51(5), 945-950.

Epstein, L. H., Temple, J. L., Roemmich, J. N., \& Bouton, M. E. (2009). Habituation as a determinant of human food intake. Psychological Review, 116(2), 384-407.

Griffioen-Roose, S., Finlayson, G., Mars, M., Blundell, J. E., \& de Graaf, C. (2010). Measuring food reward and the transfer effect of sensory specific satiety. Appetite, 55(3), 648-655.

Groves, P. M., \& Thompson, R. F. (1970). Habituation. A dual-process theory. Psychological Review, 77, 419-450

Guinard, J.-X., \& Brun, P. (1998). Sensory-specific satiety. Comparison of taste and texture effects. Appetite, 31(2), 141-157.

Havermans, R. C. (2012). Stimulus specificity but no dishabituation of sensoryspecific satiety. Appetite, 58(3), 852-855

Havermans, R. C., Janssen, T., Giesen, J. C. A. H., Roefs, A., \& Jansen, A. (2009). Food liking, food wanting, and sensory-specific satiety. Appetite, 52(1), 222-225.

Hetherington, M. M., Foster, R., Newman, T., Anderson, A. S., \& Norton, G. (2006). Understanding variety. Tasting different foods delays satiation. Physiology and Behavior, 87(2), 263-271.

Hetherington, M. M., \& Rolls, B. J. (Eds.). (1996). Sensory-specific satiety. Theoretical frameworks and central characteristics. Washington: DC US: American Psychological Association.

Higgs, S. (2008). Cognitive influences on food intake. The effects of manipulating memory for recent eating. Physiology and Behavior, 94(5), 734-739. 
Nolan, L. J., \& Hetherington, M. M. (2009). The effects of sham feeding-induced sensory specific satiation and food variety on subsequent food intake in humans. Appetite, 52(3), 720-725.

O’Doherty, J., Rolls, E. T., Francis, S., Bowtell, R., McGlone, F., Kobal, G., et al. (2000). Sensory-specific satiety-related olfactory activation of the human orbitofrontal cortex. NeuroReport, 11(4), 893-897.

Olsen, A., Ritz, C., Hartvig, D. L., \& Møller, P. (2011). Comparison of sensory specific satiety and sensory specific desires to eat in children and adults. Appetite, 57(1), 6-13.

Rankin, C. H., Abrams, T., Barry, R. J., Bhatnagar, S., Clayton, D. F., Colombo, J., et al. (2009). Habituation revisited. An updated and revised description of the behavioral characteristics of habituation. Neurobiology of Learning and Memory, 92(2), 135-138.

Rolls, E. T., Critchley, H. D., Browning, A. S., Hernadi, I., \& Lenard, L. (1999). Responses to the sensory properties of fat of neurons in the primate orbitofrontal cortex. The Journal of Neuroscience, 19(4), 1532-1540.

Rolls, E. T., \& Rolls, J. H. (1997). Olfactory sensory-specific satiety in humans. Physiology and Behavior, 61(3), 461-473.

Rolls, E. T., Rolls, B. J., \& Rowe, E. A. (1983). Sensory-specific and motivation-specific satiety for the sight and taste of food and water in man. Physiology and Behavior, 30(2), 185-192.
Rolls, B. J., Rolls, E. T., Rowe, E. A., \& Sweeney, K. (1981). Sensory specific satiety in man. Physiology and Behavior, 27(1), 137-142.

Rolls, B. J., Rowe, E. A., \& Rolls, E. T. (1982). How sensory properties of foods affect human feeding behavior. Physiology and Behavior, 29(3), 409-417.

Rolls, E. T. Sienkiewicz, Z J. \& Yaxley, S. (1989). Hunger modulates the responses to gustatory stimuli of single neurons in the caudolateral orbitofrontal cortex of the macaque monkey. European Journal of Neuroscience, 1(1), 53-60.

Rolls, B. J., Van Duijvenvoorde, P. M., \& Rolls, E. T. (1984). Pleasantness changes and food intake in a varied four-course meal. Appetite, 5(4), 337-348.

Romer, M., Lehrner, J., Van Wymelbeke, V., Jiang, T., Deecke, L., \& Brondel, L. (2006) Does modification of olfacto-gustatory stimulation diminish sensory-specific satiety in humans? Physiology and Behavior, 87(3), 469-477.

Smeets, A. J. P. G., \& Westerterp-Plantenga, M. S. (2006). Oral exposure and sensoryspecific satiety. Physiology and Behavior, 89(2), 281-286.

Thompson, R. F., \& Spencer, W. A. (1966). Habituation. A model phenomenon for the study of neuronal substrates of behavior. Psychological Review, 73, 1643.

Yaxley, S., Rolls, E. T., Sienkiewicz, Z. J., \& Scott, T. R. (1985). Satiety does not affect gustatory activity in the nucleus of the solitary tract of the alert monkey. Brain Research, 347(1), 85-93. 